\title{
A Life-Cycle Model of Habitual Dependence in Leisure Demand.
}

\section{Constantin T. Gurdgiev}

\author{
Department of Economics \\ Trinity College, Dublin \\ gurdgic@tcd.ie \\ $3^{\text {nd }}$ Draft. June, 2004.
}

\begin{abstract}
.
This model proposes an extension of the traditional habits in consumption literature to encompass the time-persistence of leisure demand. The model establishes a link between the habitual leisure and income effects, which amplifies the traditional effects on savings, investment and consumption distribution across periods. The disutility of habits stock varies with the strength of habit formation. At the same time, the wage elasticity of demand for leisure and the income elasticity of consumption are shown to be functions of the strength of habit formation. The model concludes that while habitual leisure captures the effects of persistence in leisure, it fails to reflect the time dependency properties of consumption. This warrants a new approach to modelling consumption and leisure demand that includes the possibility for time dependent and weakly inseparable consumption and leisure.
\end{abstract}




\section{Introduction.}

The general idea of time-persistence in decision making of economic agents can be traced back to the founding fathers of social sciences. As early as 1776, Adam Smith spoke of the importance of 'customary' consumption levels. Almost a century later, Alfred Marshall argued that habits play an important role in driving consumption behaviour. After the introduction of the first formal treatments of the subject by Pigou (1903) and Duesenberry (1949), there followed a long period of relative neglect of habit formation. This was partially driven by the limitations of econometric testability and the absence of the appropriate data.

Recent developments in economics have necessitated the revival of the subject. This resurgence of interest in habit formation has been provoked by the empirical failures of the representative agent time-separable-utility models. In this context, habits have been proposed in three distinct domains of macroeconomic theory. Abel (1990), Constantinides (1990) and others have argued that habits in consumption may explain some empirical regularities in finance literature, such as the equity premium puzzle. Carroll and Weil (1997), and Carroll, Overland and Weil (2000) suggested that habits may be able to explain why high growth apparently causes savings to rise, as well as the puzzling excess sensitivity of consumption to the exogenous shocks to income. In a related, yet more specialised, development, Fuhrer (1999) and others argue that habits may be necessary to explain the excess smoothness of aggregate consumption at high frequencies. All of these papers focused on introducing habit formation into a consumption component of choice. 
While insightful in providing a theoretical basis for explaining the phenomena mentioned above, none of these models have developed the analysis of the persistence in labour-leisure trade-off, apparent in the inertia in hours of labour supplied. Nor do they offer any economic reasoning as to why habituality of consumption shall, in general, be more evident in and salient to the economic agent's behaviour than habituality in leisure.

As exemplified by some studies (see Dynan (1999), for an example) microeconomic data often fails to provide support for the existence of habits in consumption. These results are contrasted by studies that show strong time-inseparability in aggregate macroeconomic data. Given the differences in measuring saving and consumption in different series, macro data might not be capturing the actual savings behaviour of the agent. Estimations based on the models accounting for consumption variation alone may be undermined by the linkages between the consumption of goods and the demand for leisure. If variation in aggregate consumption is affected by such links, while the labour supply exhibits strong persistence over time, the persistence in consumption may be driven by the interdependency of consumption and leisure demand. Similarly, measured savings might be affected by the presence of large ticket expenditures financed out of periodic savings that are linked directly to leisure demand. This direction of research was recently undertaken in Gonzales-Chapela (2003), but was pioneered earlier by Becker (1973) and others.

Empirically documented persistence in European unemployment following the oil supply shocks, as well as long term inertia in hours of labour supplied that appears, in some countries, to be independent of both wage growth and productivity enhancement are problematic in respect to traditional models of hours of work supplied. Over the years, the European labour force has not been able to accelerate both participation rates and hours supplied increases that would be consistent with the rising real wages under 
the standard models predictions. Most available data shows that the hours of work supplied by the agents have been falling over the period of the last two centuries, with the slower rates of decline in the later part of the $20^{\text {th }}$ century. Controlling for productivity growth, the response of hours worked to wage changes and income shocks is milder than predicted by traditional theories. For example, Ham and Reilly (2002) point to this shortcoming of the theoretical literature.

As an illustration, consider the data for annual hours worked per worker given in Table 1, which provide the measurement of hours supplied to labour by an average worker (Column HW) and the annual hours worked and employment/population ratios (Column LS). The figures given in Column LS are computed by setting annual hours worked as a percentage of 2080 hours per year and multiplying the result by the employment/ population ratio. The resulting figure can be considered as a measure of the proportion of the total potential hours of labour supplied in a given economy.

Excluding part-time workers, many countries in continental Europe have low annual hours worked because of their low weekly hours restrictions and long annual holidays, compared to those in the US and Japan. In fact, according to the European Economy (1995) across the EU, more people would like to work fewer paid hours than would like to work more hours at a given wage rate. This relationship breaks down in the US and Japan. Over the years, the differences between the European OECD countries and the US and Japan remain stable. At the same time, within the European sub-sample, differences in the rates of decline of hours of supplied have also remained relatively stable, pointing to the fact that the persistence in hours of labour supplied (leisure demanded) is country-specific to a large degree. 
McGrattan and Rogerson (1998) provide a survey of empirical data on the persistence of hours of work supplied. Their main conclusions confirm the above facts. The lifetime hours of labour supplied are nearly constant over time. The aggregate average of the weekly hours of work per person decreased slightly from 1950 through 1960s and then increased slightly from 1970 to 1990 . The average weekly hours supplied in the 1990s were insignificantly higher than in the 1950s. Overall, during the post war period, hours of work per employee declined by about 10 percent. At the same time, during the post war period hourly wages exhibited a persistent rise in real terms.

At a more fundamental level, traditional models often fail to account for the recent policy and environmental changes. The arguments that the labour market regulation and welfare systems in Europe have contributed to low hours supplied appear to be insufficient. The reason for this is that they cannot capture the persistence in leisure demand following the recent shifts in policy in favour of the lower regulatory burden, lower union powers and tightening of social welfare assistance. In short, policies do change while, contrary to theoretical predictions labour supply decisions appear to remain stable. Amplifying this effect is the evidence of the cross-country differences in leisure demanded.

In short, traditional models of consumption with endogenous leisure demand as well as institutional frictions models overestimate the leisure demand response to wage changes and to institutional liberalisation of the labour markets. They also fail to account for the persistence in the differences found across the countries in leisure demand and hours of labour supplied. As Ljungqvist and Sargent (1995) point out, social insurance programs and other welfare state institutions can have divergent effects on employment and cannot be a priori qualified as either employment enhancing or reducing. This apparent weakness of the mainstream models offers an opportunity for investigating the 
mechanisms of time persistence in leisure demand, and in particular the possibility for habit formation in preferences for leisure.

A deeper problem of the institutional approach to explaining the regularities in hours of labour supplied, as exemplified by Ljungqvist and Sargent (1997), Siebert (1997) and others, lies with the lack of micro foundations nesting the existence of the various institutional arrangements from the agents' utility-maximisation perspective. Arguments that rely on assuming that labour markets are constrained by the exogenously set wage contracts are acceptable, as long as we are either dealing with the command economy or abstract away from the consideration of the individual incentives to supply labour (demand leisure) in the model. Clearly, in the presence of a strong and established market forces, exogenous restrictions on wages and labour supply must be taken with a grain of salt. As long as we allow agents to trade across leisure, we can endogenise at least some of the incentives for the observed labour market contractual arrangements.

This view is also warranted by the empirical regularities. With the advancement of the service economies, the fact that the limits on hours of work increasingly fail to apply to the firms in which individuals can opt for flex-time arrangements implies that over time, we can expect an increase in the flexibility of individual labour supply. Similarly, the expansion of self-employment opportunities in modern society further strengthens the potential links between the IES in leisure and the households' consumption decisions.

Notably, as shown by Hamermesh (1995) and others, work in the off hours is frequently performed by the individuals with both high and low human capital. This implies that the aforementioned options of varying hours of work and duration of work apply equally across the wage distribution. In fact we can surmise that in modern economies, workers move between (change places of employment) and within the jobs (change time structure 
between the temporary, part-time, full-time and flex time) to better match their skills, wage expectations, and their preferences for leisure, with the attributes of position.

Echoing the above, it has long been clear that habits, traditions, and the culture of choices in general, serve as the substitutes (Becker, 1992) for long-term contracts and social, legal and economic institutions. Many political institutions and decisions are often perceived to be the direct consequences of habits. To quote James Madison's Federalist Papers, the constitution of a democratic society itself falls subject to '...that veneration, which time bestows on everything, and without which perhaps the wisest and freest of governments would not possess the requisite stability.' (J.Madison, 1787).

The presence of habits in preferences captures individual motivation for smoothing demand for leisure. Thus, implicitly, this paper argues that economic institutions in labour markets within democratic society may evolve to accommodate this inertia, such as a higher degree of restrictions on labour mobility and stronger vacation and time-off allowances.

Hence, it appears justified to concentrate on the microeconomic determinants of the differences in labour supply within the context of introducing time inseparability into the agents' utility function. In light of this, current research extends the habit formation mechanism to labour supply (leisure demand) behaviour of the agents. To my knowledge, as of today, there exist no work that proposes such a microeconomic specification.

The goals inherent in this research are manifold. First, the objective is to establish how the introduction of habits in leisure affects the dynamic behaviour of the traditional habits-in-consumption models with respect to unexpected labour income shocks. Second, to generate a model-based approximation of the sluggish response to 
wages/income shocks observed in data and so far not replicated by the traditional LCRBC models. Third, we want to establish a dynamic connection between labour supply and consumption that would allow us to more clearly distinguish between the income effects of labour supply on consumption choices, the traditional substitution effect across the two choices and the inertia in labour supply effects on consumption responses to income changes.. Along these lines, the proposed model will be able to establish a firm set of micro-foundations for explaining the observed persistence in the labour supply (leisure demand) decisions without resorting to the exogenous set of institutional assumptions.

With these goals in mind, the paper proceeds as follows. Part 1 below introduces the basic model with habit formation in leisure and obtains a general form of the Euler equations linking demand for leisure and consumption over time in the environment of general uncertainty. Part 2 proceeds to derive closed-end solutions to the deterministic steady state demand for leisure and consumption. Following the steady state analysis we derive the dynamics of the model along the adjustment path to the steady state and conclude with a brief discussion of the model under a set of specific assumptions concerning the form of the utility function. Appendix 1 provides mathematical details.

\section{Part 1. A Model of Leisure Demand with Dynamic Habits.}

Building on the works by Muellbauer (1988), Constantinides (1990), Carroll (2000), and others who pioneered the applications of time persistence in consumption, the following work introduces two main innovations. First, we augment the model to include the endogenous labour supply decisions. Second we introduce time-inseparability into the labour supply (leisure demand) in the style of inward-looking habits. As shown below, the resulting model yields interesting results vis-à-vis the time persistence of leisure 
demand. We begin by postulating and solving a baseline model in the presence of habit formation in leisure.

\subsection{The Baseline Model.}

Finitely lived agents maximise an expected life-time utility of consumption $C_{s}$, leisure $1-L_{s}$ and the stock of habits, $h_{s}$ :

$\max E_{t}\left[\sum_{s=t}^{T} \beta^{s-t} U\left(C_{s}, L_{s}, h_{s}\right)\right]$,

subject to the standard cash on hand constraint

$x_{t+1}=R\left(x_{t}-c_{t}\right)+w L_{t+1}$

the evolution of habit stock constraint (law of motion for habits):

$h_{t+1}=h_{t}+\lambda\left(L_{t}-h_{t}\right)$

and the labour force participation constraint:

$0<L_{t}<1$

Equation (4) restricts the model to those agents who are currently in the labour force and supply non-zero hours of labour. As usual, it is straightforward to extend this model to include household production. Another necessary constraint is the restriction on consumption to be strictly positive in any period of life, so that $C_{t}>0 \forall t>0$.

Equation (2) is a standard cash-on-hands constraint where wage is assumed to be constant and exogenously given, while $R=1+r$ is a constant gross interest rate. The assumptions of constant rate of return on the risk-free deposits and constant wage rate are imposed for the sake of simplicity. Carroll (2000) shows that the general method of solving the present class of problems will hold in case whenever the households have 
access to both a risk-free storage technology and the risky assets with time-variant stochastic rate of return. At the same time, the model can be extended to include productive sector of economy with subsequent endogenising of the wage rate into the decisions of the firms. However, since the present study focuses on the demand side for leisure and the tradeoffs between leisure and consumption, endogenous wage determination and/or time-varying rate of return to the risk free asset are not expected to yield any significant modifications of the analysis presented below. In addition, both assumptions are common to the literature concerning habits.

Equation (3), a law of motion for the habit stock, specifies the process of evolution of the history of the past labour supply decisions. Earlier versions of the habit-formation-inconsumption models relied on setting the stock of habits to be equal to the level of consumption in previous period. In such a case, the law of motion for habits is: $h_{t+1}=\alpha h_{t}$. As shown in Carroll (2000) this specification under the plausible parameterisation of the utility function can lead to an infinitely negative utility. Specifically, this applies to the cases of low consumption levels. Equation (3) above avoids this pitfall. This is important in the context of the current model, since we restrict the endowment of time to be 1 , making both labour supply and leisure demand decisions to be contained within the $(0,1)$ interval.

Finally, in the above specification, $\lambda$ indexes the speed at which habits catch up with leisure demand. If $\lambda=0$, habits enter the utility of leisure as a constant multiplicative factor. When $\lambda=1$, habits in the current period become fully determined by the past period's choice of leisure, corresponding to the case where habit stock fully catches up with leisure demand within one period following an exogenous shock. For $\lambda=0.3$ the half-life of habits adjusting to the new steady state level of leisure demand will be 
approximately 2 periods. At the same time this implies that the history of leisure demand over the last 10 periods will account for over $95 \%$ of the current period reference stock of habits. As $\lambda$ falls to 0.1 , the half-life increases to 7 periods and more remote history of past leisure decisions becomes more prominent in the determination of the current period habits. In fact, history of labour supply over the past 10 periods will account for only $63 \%$ of the current habits stock in this case.

Note that in the utility function specification (1) we assume that leisure influences utility via the dis-utility of labour, so that $U_{l}<0, U_{l l} \geq 0$ In this case, habituality of leisure implies that $U_{h}>0, U_{h h} \leq 0$. These assumptions allow us to derive a closed end solution for leisure demand in the steady state. It is straightforward to derive implicit (but not closed end) solutions in the case where leisure directly enters the utility function.

The Bellman equation for the problem is:

$V_{t}\left(x_{t}, h_{t}\right)=\max _{\left\{C_{t}, L_{t}\right\}} U\left(C_{t}, L_{t}, h_{t}\right)+\beta E_{t}\left[V_{t+1}\left(x_{t+1}, h_{t+1}\right)\right]$

Taking the first order conditions with respect to consumption and leisure, and applying the envelope theorem for $x_{t+1}$ as shown in the Appendix 1:

$$
\begin{aligned}
& U_{t}^{C}=R \beta E_{t}\left[U_{t+1}^{C}\right] \\
& U_{t}^{L}=E_{t}\left[-w V_{t+1}^{X}-\beta \lambda V_{t+1}^{h}\right]=-w U_{t}^{C}-\lambda \beta E_{t} V_{t+1}^{h}
\end{aligned}
$$

Equation (6a) is the standard Euler equation for consumption that arises in the case of time-separable utility. Under the assumption of separability in leisure demand and consumption in the instantaneous utility function, this implies that consumption fully adjusts to the new steady state at the impact following an exogenous shock. The Euler equation for labour supply (6b) implies that the marginal disutility of labour in period $t$ is an increasing function of the value of the marginal utility of consumption in the 
following period. The latter is measured in terms of disutility from leisure foregone today, less the marginal value of the habit stock changes resulting from the period $t$ labour supply decisions.

In a benchmark case of no habits:

$U_{t}^{L}=-w U_{t}^{C}=R \beta E_{t} U_{t+1}^{L}$

Equation (6b.NH) states that in the absence of habit formation in leisure, labour supply fully adjusts to the new steady state at the impact of an exogenous shock. Since in any period marginal utility of leisure is a scalar multiple of the marginal utility of consumption, agents treat leisure as a substitute to consumption in the sense discussed in Heckman (1974). Hence the consumer will have an incentive to select lower leisure and higher consumption in response to an increase in the price of leisure, $w$.

In our model, however, this standard effect is contrasted by the intertemporal substitution trade-offs across the two choice variables, discussed below. Yet, an initial glimpse of the habitual effect of leisure can be gained from looking at equation (6.b). The second component of equation (6.b), on the right hand side, is the effect that habits in leisure exert onto the households' willingness to trade between consumption and leisure over time. Clearly, since $V_{t+1}^{h}>,<0 \Leftrightarrow-U_{t}^{L}>,<w U_{t}^{C}$, the habits in leisure effect on consumption and leisure substitutability across time may either augment or counter the standard effect mentioned above. Specifically the direction of the interaction will depend on the size of the intertemporal elasticity of substitution (IES) in consumption relative to the IES in labour supply.

Again applying the envelope theorem for $V_{t+1}^{h}$, as shown in the Appendix, and substituting into the first order condition $(6 b)$ : 
$U_{t}^{L}=R \beta E_{t}\left[\beta\left(\lambda U_{t+2}^{h}-(1-\lambda) U_{t+2}^{L}\right)+U_{t+1}^{L}\right]-\beta E_{t}\left[\lambda U_{t+1}^{h}-(1-\lambda) U_{t+1}^{L}\right]$

Equations (7) and (6a) are the two Euler equations for leisure and consumption respectively. As desired, in the case of no habits in leisure, equation (7) above fully reduces to a standard solution, given by equation (6b.NH).

In equation (7), term

$E_{t}\left[\beta\left(\lambda U_{t+2}^{h}-(1-\lambda) U_{t+2}^{L}\right)+U_{t+1}^{L}\right]$

captures the effect of changing leisure today on the future income, first via changes in labour income in the next period due to changes in future leisure demand, and second, via the effect of the habit stock on cash-on-hand in the following period. At the same time, term $E_{t}\left[-\lambda U_{t+1}^{h}+(1-\lambda) U_{t+1}^{L}\right]$ captures the effects of changes in today's labour supply on the next period choice of leisure, firstly via changes in habit stock of leisure and secondly via an income effect.

Consider the following two cases:

Case 1: Habits are a multiplicative constant of past leisure demand, so that $\lambda=0$, in which case, $U_{0, t}^{L}=R \beta E_{t}\left[U_{t+1}^{L}-\beta U_{t+2}^{L}\right]+\beta E_{t}\left[U_{t+1}^{L}\right]$.

This implies that marginal dis-utility of labour today is equal to a discounted sum of the expected marginal value of future consumption, plus the expected marginal disutility of leisure tomorrow. In addition we subtract the trade-off between leisure and consumption tomorrow arising due to the leisure effect on cash-on-hand in the following period. This implies that leisure demand shall be 
consumption and leisure driven, with the habits effect being fully determined by consumption changes alone.

$\underline{\text { Case 2: }}$ Habits are fully catching up with labour supply, so that $\lambda=1$, in which case $U_{t}^{L}=R \beta E_{t}\left[\beta U_{t+2}^{h}+U_{t+1}^{L}\right]-\beta E_{t}\left[U_{t+1}^{h}\right]$, which implies that the marginal utility of leisure today must be equal to the discounted expected marginal utility of consumption tomorrow (income effect) less the effect of habit stock changes on leisure demand tomorrow. Hence, any change in leisure from period to period is influenced by the changes in habit stock.

The above discussion can be made more transparent by observing that the substitution of equation (6.a) into equation (6.b), after applying the Envelope theorem result for $h_{t+1}$ :

$U_{t}^{L}=-\frac{w}{R}(r+\lambda) U_{t}^{C}-\beta E_{t}\left[\lambda U_{t+1}^{h}-(1-\lambda) U_{t+1}^{L}\right]$

From equation (8), the marginal disutility of labour supply can be broken down into two major components. The marginal utility of consumption due to foregone leisure that depends on both the opportunity cost of consumption today, $r$, and the habits cost of adjusting labour supply, $\lambda$. The second component is the marginal effect of present labour supply decisions on the future marginal utility of leisure through the direct effect on leisure demand tomorrow plus the effect on habits stock of leisure.

\subsection{Specific Form.}

Next we specify the within period utility function:

$U\left(C_{t}, L_{t}, h_{t}\right)=\frac{C_{t}^{1-a}}{1-a}-\left[\frac{\left(L_{t} / h_{t}^{\sigma}\right)^{1-b}}{1-b}\right]$ 
Equation (9) represents a version of the more general Box-Cox specification in the absence of person-specific and age-specific taste shifters. In this specification, leisure is a habitual good in the sense that holding the marginal utility of wealth constant, $\frac{d L_{t}}{d h_{t}} \neq 0$ (as in Becker, 1992). Furthermore, leisure will be addictive whenever $\frac{d L_{t}}{d h_{t}}<\frac{L_{t}}{h_{t}}$ around the steady state values of leisure and habit stock (following Becker and Murphy, 1998). In equation (9), $\sigma$ indexes the importance of habits in the utility. If $\sigma=0$, then habits do not enter the determination of labour supply and agents care only about the level of leisure demanded (labour supplied) in any given period. For any $0<\sigma<1$, consumers care about both leisure demand today and how it compares with the habit stock. Finally, in the case of $\sigma=1$, consumers care only about the extent to which leisure consumption compares with a stock of habits. For illustration purposes, consider the case of $\sigma=0.5$. A person supplying 0.2 units of labour today, having a habit stock of 0.1 unit will then have the same utility as a person with both supply level and a stock of habits equal to 0.4. Increasing $\sigma$ to $2 / 3$ implies that the first agent will have the same utility as a person with either 0.4 units of labour supply and higher habit stock, or with the habit stock of 0.4 units and labour supply in excess of 0.8 units.

Our choice of specification (9) is supported by the following reasons:

1) Whenever labour supply is positive, habits will always be positive, so that the CRRA utility function does not allow for a negative infinite utility.

2) Equation (9) generates non-decreasing absolute risk aversion and permits for a precautionary motive for saving (see Note 1 for details).

3) Specification (9) avoids the existence of a 'bliss point' beyond which additional consumption and/or leisure demand reduce utility. 
Define $z_{t}=\frac{L_{t}}{h_{t}}$. From definition (9), using equation (8), the Euler equations for leisure and consumption (6.a) and (7) are given by:

$$
\begin{aligned}
C_{t}^{-a}=R \beta E_{t}\left[C_{t+1}^{-a}\right] \\
\left(\frac{L_{t}}{h_{t}^{\sigma}}\right)^{-b}=R \beta^{2} E_{t}\left\{\left(\frac{L_{t+2}}{h_{t+2}^{\sigma}}\right)^{-b}\left(\frac{h_{t+2}}{h_{t}}\right)^{-\sigma}\left(\lambda-1-\lambda \sigma z_{t+2}\right)\right\}+ \\
+\beta E_{t}\left\{\left(\frac{L_{t+1}}{h_{t+1}^{\sigma}}\right)^{-b}\left(\frac{h_{t+1}}{h_{t}}\right)^{-\sigma}\left[R+1-\lambda+\lambda \sigma z_{t+1}\right]\right\}
\end{aligned}
$$

Similarly, for equation (8):

$$
h_{t}^{-\sigma}\left(\frac{L_{t}}{h_{t}^{\sigma}}\right)^{-b}=\frac{w(r+\lambda)}{R} C_{t}^{-a}+\beta E_{t}\left\{\left(1+\lambda \sigma z_{t+1}-\lambda\right)\left(\frac{L_{t+1}}{h_{t+1}^{\sigma}}\right)^{-b} \frac{1}{h_{t+1}^{\sigma}}\right\}
$$

Note that in the case of no habits, $\lambda=1, \sigma=0$, (7) and (10a)-(10c) yield Euler equations for the standard PIH model. Specifically:

$$
U_{t}^{L}=R \beta E_{t}\left[U_{t+1}^{L}\right]
$$

$$
L_{t}^{-b}=\beta E_{t} L_{t+1}^{-b}+w C_{t}^{-a}
$$

This implies that the marginal disutility of labour today is equal to the present discounted value of the marginal disutility of labour tomorrow. At the same time, by equation (10c. $\mathrm{NH})$ the real value of the marginal disutility of labour today in terms of consumption brought forward one period to tomorrow is equal to the sum of two components. The first component captures the real present discounted value of foregone future leisure that arises from the income effect of the current labour income being carried over to tomorrow. The second component is the marginal utility of consumption tomorrow arising from the addition of the carried over labour income.

Combining equations (7.NH) and (10c.NH) and assuming that $R \beta=1$ we have: 
$L_{N H, t}=w^{-1 / b} C_{N H, t}^{a / b}$

As with the general case, no explicit closed end solution exist to the problem in the presence of uncertainty. However, Euler equations $(10 \mathrm{a}, \mathrm{b})$ can be numerically solved for optimal values of $C_{t}, L_{t}$ at some set of grid points in $(x, h)$ space. Instead we will focus on analytical solutions in the case of perfect foresight.

\section{Part 2. Perfect Foresight Solutions.}

Many macroeconomic problems can yield useful insights whenever it is possible to solve for the deterministic steady state values of the parameters of interest. As the following shows, it is possible to solve analytically for the steady state values of the perfect foresight version of our model. It is also possible to solve for the dynamics of the model along the adjustment path to the steady state.

\subsection{Solutions for the Steady State.}

Define $z_{t}=L_{t} / h_{t}$ to be the ratio of labour supply to habits stock. Assume, as standard (see Carroll, 2000) that in the perfect foresight solution case, consumption, labour supply and habits grow at constant rates:

$$
\begin{aligned}
& C_{t+i}=\xi_{C}^{i} C_{t} \\
& L_{t+i}=\xi_{L}^{i} L_{t} \\
& h_{t+i}=\xi_{L}^{i} L_{t}
\end{aligned}
$$

Note: equations (12a)-(12c) hold in the case of no habits as well.

Defining $k_{t}=\beta\left(\lambda-1-\sigma \lambda z_{t}\right)$, as shown in the Appendix 1, we can solve for the growth rate in labour supply in the steady state: 
$\xi_{L, S S}=(R \beta)^{1 /[b-\sigma(b-1)]}$

This implies that steady state ratio of labour supply to habits stock is

$z_{S S}=\frac{\xi_{L, S S}-1+\lambda}{\lambda}$

Hence, under the assumption that $R \beta=1$ we have:

$\xi_{L, S S}=\xi_{C, S S}=z_{S S}=1$

Equating the present discounted value of the household's resources to the present discounted value of the household's consumption, as shown in the Appendix 1, we obtain:

$C_{S S}=w L_{S S}$

Using equation (8), together with the Euler equation (6a) and the fact that, as shown in the Appendix 1,

$\lambda U_{t}^{h}-(1-\lambda) U_{t}^{L}=U_{t}^{L}(\lambda-1-\sigma \lambda z)$

we obtain:

$U_{t}^{L}=-\frac{w(r+\lambda)}{\left(1+k \xi_{L, S S}\right)} U_{t}^{C}$

By equations (9) and (15) we can solve for the steady state level of labour supply:

$L_{S S}=\left(\frac{w^{1-a}(r+\lambda)}{(r+\lambda-\sigma \lambda)}\right)^{\frac{1}{\sigma b-\sigma-b+a}}$

Setting $\lambda=\sigma=0$ in equation (18) attains the solution for the case of no habits:

$L_{N H, S S}=w^{\frac{1-a}{a-b}}$

As desired, equation (18.NH) confirms the result given in equation (11) under the steady state condition relating consumption and labour income, i.e. equation (16). 
From equations (18.NH) and (18):

$$
\frac{L_{S S}}{L_{N H, S S}}=w^{\frac{\sigma(1-b)(1-a)}{(\sigma b-\sigma-b+a)(a-b)}}\left(\frac{r+\lambda}{r+\lambda-\sigma \lambda}\right)^{\frac{1}{\sigma b-\sigma-b+a}}
$$

Likewise, in equation (18), setting $\lambda=0$ alone, so that habits stock is a multiplicative constant of past labour supply decisions implies that agents will choose to supply more labour hours in the steady state than in the case of no habitual dependence in leisure.

In this specification, $\lambda$ measures the speed at which the habits stock catches up with the past period demand for leisure. Different studies of habits in consumption assume varying values of $\lambda$ for parameterisation. Models that use habit formation in consumption to explain the equity premium puzzle assume higher values of $\lambda$ than those where habit formation explains aggregate savings behaviour and growth. In general, a higher speed of catching up implies a shorter period of transitional dynamics. In our case, from equation (14), $\forall 0<\lambda<1, z \geq 1$ and in particular, as $\lambda \rightarrow 1$, then $z \rightarrow \xi_{L}$. This implies that as the habit stock catches up with leisure demand, the agents value more leisure in the recent past, relative to the leisure demanded in a more distant past. As $\lambda \rightarrow 0$, then $z \rightarrow \infty, h_{t} \rightarrow 0$. Clearly, $\frac{d z}{d \lambda} \leq 0$ as desired in order to prevent habitual stock of leisure from generating addictive properties, defined by Becker and Murphy (1988).

For the steady state values of leisure demand and habits stock, $\xi_{L}=1$, so that in the steady state neither habits nor leisure demand exhibit any growth. Then the ratio of leisure demand to habits is $z=1$. Thus in the steady state, the habitual stock of leisure fully catches up with leisure demand within each period. 
Equation (18) provides a closed end solution for the steady state demand for leisure as a function of the speed at which habits catch up with the demand, the strength of habits and the wage rate. As in the standard habits-in-consumption models, the level of habits stock does not determine the steady state value of leisure. In fact, as in the standard habit formation models, the introduction of habits in leisure does not change the risk-aversion properties of the utility function at any point in time since the stock of habits is effectively fixed in any given moment. Thus by equation (9), $a$ and $b$ continue to act as the coefficients of the relative risk aversion for consumption and leisure respectively.

However, the habits stock does evolve over time so that the intertemporal elasticity of substitution for leisure is no longer given by the inverse of the CRRA coefficient. As habits make it more possible for consumers to postpone leisure demand in response to income shock (or equivalently to a wage shock), the infinite horizon intertemporal elasticity of substitution (IES) increases with habits. The reason for this is that marginal disutility of habits implies that in every period, households are interested in postponing the adjustments to the demand for leisure. The incentives to do so are directly proportional to the strength of the habits effect in the utility function. Hence, in our case, the infinite horizon IES for leisure is given by $(b-\sigma(b-1))^{-1}$. In the short run, as standard with the habitual specifications in equations (9) and (3), the IES with respect to temporary changes in the interest rate, as the period of the temporary change approaches zero, the IES falls to the inverse of $b$.

\footnotetext{
Proposition 1. In case of $r=\delta$, faster convergence of habits $(\lambda \uparrow)$ will result in lower (higher) labour supply whenever $a<,>b-\sigma(b-1)$. Stronger effect of habits on the marginal utility of leisure ( $\sigma \uparrow$ ) will be associated with the lower steady state value of labour supply whenever $a<b-\sigma(b-1)$.
} 
However, in case of $a>b-\sigma(b-1)$ stronger habits will result in higher labour supply whenever $r+\lambda-\sigma>0$. Furthermore, whenever $a<,>b+\sigma(1-b)$ habitual leisure demand is lower than leisure demand in case of no habits, i.e. $L_{S S}<,>L_{S S N H}$.

Proof: directly from equations (18) and (18.NH).

First, note that this result is more general than the one obtained in Faria and LeonLedesma (2004). In their case, the effects of habits in labour supply on the household demand for leisure are unambiguous and independent of the parameter values in the model. The authors establish that whenever labour effort is habit forming due to social incentives for overtime work, labour supply will exceed, in the steady state, the level of hours supplied in the neoclassical model. In contrast our result allows for both possibilities. Whenever $a>b-\sigma(b-1)$, our model results coincide with Faria and Leon-Ledesma (2004). However, the opposite occurs when either the habits are relatively weak $\left(\sigma<\frac{b-a}{(b-1)}\right)$ or the elasticity of consumption substitution is low relative to that of the elasticity of leisure substitution (i.e. $b$ is large relative to $a$ ).

Note that since the speed at which the habits stock catches up with leisure demand does not enter determination of the infinite horizon IES, the first effects outlined in Proposition 1 are driven solely by the relative strength of the IES in consumption. The overall level of labour supply in the steady state relative to the case of no habits, however, depends on the speed of adjustment in the stock of habits. The reason for this is simple. When speed of adjustment is high, or the strength of habits is low, so that $r+\lambda-\sigma>0$, agents face a higher opportunity cost of leisure along the adjustment path. This implies that they are willing to postpone leisure demand. However, at the 
same time, lower IES in consumption $(a>b-\sigma(b-1))$ implies that they are simultaneously unwilling to scale down their demand for goods. This means that along the transition path they do not accumulate sufficient level of savings to finance the higher demand for leisure in the future.

Controlling for leisure demand, along the approach path to the steady state, agents with higher habits will have higher consumption and savings $\left(s_{t}\right)$ than agents with no habit formation in leisure whenever $a>b+\sigma(1-b)$. This result follows from the following: $s_{H t}-\left.s_{N H t}\right|_{\bar{L}}=\left(x_{H t+1}-x_{H t}\right)-\left.\left(x_{N H t+1}-x_{N H t}\right)\right|_{\bar{L}}=\left.R\left(C_{N H t}-C_{H t}\right)\right|_{\bar{L}}$

Proposition 2. Whenever $a<,>b+\sigma(1-b)$, the wage elasticity of substitution of labour supply will be positive (negative). Furthermore, the absolute value of the wage elasticity of leisure demand will be decreasing in the strength of habits in the utility, $\sigma$, and independent of the speed with which the habits adjust toward the steady state, $\lambda$.

Proof: from equation (18)

$$
\frac{d \log L_{S S}}{d \log w}=\frac{1-a}{a-\sigma(1-b)-b}\left\{\begin{array}{l}
>0 \text { if } a<b-\sigma(b-1) \\
<0 \text { otherwise }
\end{array}\right.
$$

For any $a>1$ the result follows.

The intuition behind the above results is straightforward. Habits reduce the household willingness to adjust labour supply in response to exogenous shocks both across time and vis-à-vis consumption within each period. Higher IES in consumption relative to labour supply implies that the above habits effect is amplified. Hence exogenous change in wages has a dual effect on household choices. The first effect is due to a smoothing motive: as the households smooth their leisure demand, they adjust their labour supply so as to account for the negative effect of future habits on the marginal utility of leisure. 
As s result, the wage elasticity of labour supply falls. On the other hand, households are slowly adjusting leisure demand against consumption. Changes in consumption allow for the smoothing of leisure demand are limited by the intertemporal willingness of consumers to adjust both their labour supply and their consumption. Thus higher intertemporal elasticity of substitution in consumption acts to decrease responsiveness of leisure demand to wage changes reinforcing the direct effect of habits.

This result is important in the context of the traditional models. Many empirical estimates of the wage elasticity of labour supply show that the major puzzle in modern economic theory is the prediction of the high wage elasticity of labour supply in comparison to the empirical evidence. McGrattan and Rogerson (1998) provide an extensive survey of empirical literature concerning this theoretical puzzle. They argue that theoretical predictions of the macroeconomic models imply that the elasticity of substitution between consumption and leisure should be around 1. The reason for this is that leisure per capita shows no apparent trend over time even in the presence of rising wages. As shown in the present model, habitual dependence of leisure demand may provide at least partial resolution of the puzzle.

In addition, McGrattan and Rogerson (1998) state that although the aggregate hours of work remained relatively constant over time, the data shows large and persistent reallocations of leisure demand across various segments of population. This generates yet another difficulty for the traditional macro models of labour supply. According to the authors, "whether theory can accpunt simultaneously for the relative constancy of aggregate hours of worked... and the pattern of reallocations of hours worked across [the groups] is an open question' (McGrattan and Rogerson (1998), page 3). Our model allows for the inter-group variation in the hours of leisure demanded both along the transition path (by introducing heterogeneity in $\lambda$ ) and in the steady state (by assuming 
inter-group variation in $\sigma$ ). It furthermore allows for the aggregate hours of work per household to remain persistent over time.

\subsection{Dynamics around the Steady State.}

Finally as in Carroll (2000) we can solve for the dynamics of the perfect foresight model. By equations (12.a)-(12.c) and the definition of $z_{t}$ we have:

$z_{t}=\xi_{L, t} \frac{z_{t-1}}{1-\lambda+\lambda z_{t-1}}$

Using equations (9), (20) in (7) under the assumption that $R \beta=1$, as shown in the Appendix 1, we have:

$\xi_{L, t+2}^{-b}=-\frac{\left(1-\lambda+\lambda z_{t+1}\right)^{-\sigma(b-1)}\left\{\left(1-\lambda+\lambda z_{t}\right)^{-\sigma(b-1)}-\xi_{L, t+1}^{-b}\left[1-k_{t+1}\right]\right\}}{k_{t+2} \xi_{L, t+1}^{-b}}$

where $k_{t+1}=-\beta\left(\lambda \sigma z_{t+1}+1-\lambda\right)$ as defined earlier.

Alternatively the above equation can be re-written as:

$$
\xi_{L, t+1}^{-b}=\frac{\left[1+\lambda\left(z_{t}-1\right)\right]^{\sigma(b-1)}}{\beta\left[1+\lambda\left(\sigma z_{t+1}-1\right)\right]}\left\{1+\beta\left[1+\lambda\left(\sigma z_{t}-1\right)\right]-\xi_{L, t}^{-b}\left[1+\lambda\left(z_{t-1}-1\right)\right]^{\sigma(b-1)}\right\}
$$

From equation (21), the growth rate in labour supply along the adjustment path will depend on the size of the habits stock relative to labour supply at any given point in time. Note, we assume that $1+\lambda\left(\sigma z_{t+i}-1\right)>0$. However, along the adjustment path, $1<z_{t+i}>,<1 / \sigma$ may hold. Early along the adjustment path, $z$ may be sufficiently large to keep $z_{t+i}>1 / \sigma$. As $z$ evolves over time, it moves closer to 1 . Thus, there exists a period of switch in the growth rate direction, $t+i$, where $z_{t+i}<1 / \sigma$. This implies that stronger habits in the utility (higher $\sigma$ ), or a faster convergence in habits to the steady 
state level (higher value of $\lambda$ ) will have different effects on the growth rate in labour supply depending on how far away from the new steady state we are. In general, the sign of the growth rate will be invariant along the adjustment path. However, the speed of the adjustment will depend negatively on the strength of habits in the utility.

\section{Proposition 3. The speed of adjustment in labour supply toward the new steady state will depend negatively on the strength of habits in the utility, $\sigma$.}

Proof: directly from equation (21).

\subsection{Log-Utility in Leisure and Linear Habits: A special case.}

In line with the established literature it is worth to consider briefly a specific form of the utility function given in equation (9) that corresponds to the choice of $b=1$. In this case the instantaneous utility function takes a logarithmic form in labour effort, which implies that labour supply and habits stock are separable within each period. The linear nature of the relationship between the habits stock and leisure demand implies that intertemporal elasticity of substitution in consumption is dominated by the motive for smoothing of leisure demand. Thus, assumption that $a>1$ results in a more clear-cut analysis of the habits effect on leisure decisions of the households.

Equations (18) and (18.NH) in this case yield:

$$
L_{S S}=\frac{1}{w}\left(\frac{r+\lambda}{r+\lambda-\sigma \lambda}\right)^{1 /(a-1)}=L_{N H, S S}\left(\frac{r+\lambda}{r+\lambda-\sigma \lambda}\right)^{1 /(a-1)}
$$

This implies that Propositions 1-2 hold at $a>b=1$. Thus wage elasticity of labour supply is -1 , independently of the strength of habits and/or the speed of habits convergence to the steady state. At the same time, the strength of habits in the utility, $\sigma$, 
and the speed of habits convergence, $\lambda$, both have a positive effect on the labour supply in the steady state. Since the habits stock is completely separable from the labour supply effect on the utility, log utility specification of preferences implies that response of the labour supply to changes in the wage rate is driven by two forces. The first force is the need to smooth leisure demand over time that arises from habits effect. The second force is the direct substitution between leisure demand and consumption. No interaction between substitution across the two goods and habits stock arises in the case of log utility specification.

\section{Proposition 4. In the case of a logarithmic utility in leisure, along the adjustment path to the steady state, the growth rate of leisure demand depends negatively on the strength of habits in the utility function $(\sigma)$, and the speed at which habits catch up with the labour supply $(\lambda)$.}

Proof: by equation (21) and (20) above, setting $b=1$ the result follows.

\section{Conclusions.}

Use doth breed habit...

W. Shakespeare, The Two Gentlemen of Verona.

Building on the traditional habits in consumption literature, our model presents two major innovations. First we augment the standard model by including endogenous labour supply. Unlike a small number of recent papers (for example, see Graham, 2003), our model derives explicit closed end solutions for the variables of choice under both general and specific functional form assumptions. Second, we introduce time inseparability in the household's preferences over leisure demand/labour supply.

As established above, the presence of habits in individual preferences for leisure acts to account, at least in part, for some of the empirical regularities found in macro data. 
Incorporating time dependency in leisure demand allows for modelling persistence in hours of labour supplied in response to exogenous shock to wages. Thus, in contrast with both habits-in-consumption and standard macroeconomic models of consumption, our model better captures the empirically observed low wage elasticity of demand for leisure. In contrast to the present model and the stylised macroeconomic facts, habit formation in consumption models that commonly assume exogenous labour supply, achieve time persistence in consumption at the expense of inertia in leisure demand. Inclusion of endogenous labour supply in the habits-in-consumption models, as shown in Graham (2003), does not alter this shortcoming.

The model proposed in the present paper generates, in a case of no aggregate uncertainty, a stable and well-defined steady state for leisure that is independent of the actual stock of habits. However, as habits stock evolves over time, consumers have an incentive to postpone any adjustment in leisure demand so that the infinite horizon intertemporal elasticity of substitution in leisure does increase with habits stock. This results in the added incentives for households to postpone adjustment in the leisure demand over and above the traditional substitution and income effects.

As shown in the Proposition 1, time inseparability in leisure demand enters the determination of the steady state hours of labour supply via the relative effects of habits on utility $(\sigma)$ and the rate at which the habits stock catches up with leisure $(\lambda)$. Whenever households are more willing to trade across time in consumption than in leisure, the smoothing effects of habits in leisure dominate household decision making. The households with a higher importance of habits in the utility, or households with a higher speed at which habits adjust to the steady state, will demand more leisure and supply less labour in response to the positive wage shock. In this case, leisure and consumption will act as gross compliments. For the households, which are more willing 
to trade in the leisure component of the utility than in consumption across time, stronger habits effect will imply that leisure and consumption will act as gross substitutes.

Overall, households with weaker intertemporal elasticity of substitution in consumption than in leisure will have a lower labour supply in case of habits than in case of no habits in leisure.

Due to presence of habits, these effects translate into the lower, in the absolute value, the wage elasticity of substitution in leisure than in the case of intertemporally separable preferences for leisure. Proposition 2 establishes this fundamental effect of introducing time-inseparability in leisure into the within-period utility function.

Finally, the model allows for determining the speed of adjustment in labour supply along the path to the steady state in response to an exogenous shock to wages. From Proposition 3, growth rate in leisure demand will depend negatively on the strength of habits in the utility function and the speed at which habits catch up with the demand for leisure.

As expected these results replicate some of the main implications of the habit formation in consumption models without resorting to an assumption that agents are unwilling to adjust their immediate consumption in response to changes in income, and by simultaneously addressing the issue of time persistence in hours of labour supplied. Given the empirically documented strong time-persistence in leisure demand, both at macro and micro data levels, the proposed model appears to provide a more intuitive and a potentially better fitting, approach to modelling household behaviour, than habit formation in consumption mechanism. However these positive results come at the expense of sacrificing the main advantages of the standard habits-in-consumption models. Namely, in our model since consumption is assumed to be non-habitual, gradual 
adjustment of leisure demand implies that consumption acts as a shock-absorbing variable. This yields jump-discontinuous instantaneous adjustment dynamics in consumption.

The latter shortcoming of the model presented above warrants examination of the alternative specifications with an aim of developing a plausible macroeconomic model that would account simultaneously for the delayed response in consumption and leisure demand. Such a model may incorporate the possibility for joint determination effect of consumption and leisure demand on the reference stock of habits.

\section{Bibliography.}

Abel, A.B. "Asset Prices under Habit Formation and Catching up with the Joneses". The American Economic Review, V80, Issue 2 (May 1990), 38-42

Ball, L. “Aggregate Demand and Long-Run Unemployment”, Manuscript, Johns Hopkins University, 1999.

Becker, G.S. "Habits, Addictions and Traditions”, Kyklos 45, number 3, 1992, 327-346.

Becker, G.S., Murphy, K.M. “A Theory of Rational Addiction”, The Journal of Political Economy, V. 96, 1988, 675-700.

Carroll, C.D. "Risky Habits and Marginal Propensity to Consume Out of Permanent Income”, Manuscript, Johns Hopkins University, 1999.

Carroll, C.D. "Requiem for the Representative Consumer?", Manuscript, American Economic Association, January 2000.

Carroll, C.D., Overland, J., Weil, D.N. "Saving and Growth with Habit Formation”, Manuscript, The American Economic Review, forthcoming, 2001.

Carroll, C.D., Weil, D.N. “Saving and Growth: A Reinterpretation”, NBER Working Paper, number 4470, 1997. 
Constantinides, G.M. "Habit Formation: A Resolution of the Equity Premium Puzzle", The Journal of Political Economy, V.98, Issue 3, 519-543, 1990.

Dynan, K. "Habit Formation in Consumer Preferences: Evidence from Panel Data", Mimeo, Board of Governors of the Federal Reserve. 1999.

European Economy "Performance of the EU Labour Markets”, European Commission, B-1049, Brussels, 1995.

Faria, J. R. and M. A. Leon-Ledesma (2004) "Habot Formation, Work Ethics, and Technological Progress", Manuscript, Department of Economics, University of Kent, UK.

Fuhrer, J.C. "Habit Formation in Consumption and its Implications for the Monetary Policy Models”, The American Economic Review, forthcoming. 1999.

Gonzales-Chapela, "The price of recreation goods as a determinant of labor supply", Manuscript, Universitat Pompeu-Fabra, September 2003.

Graham, L., "Some macroeconomic effects of habit formation in consumption", Manuscript, University of Warwick, 2003.

Ham, J., Reilly, K.T. “Testing intertemporal substitution, implicit contracts and hours restriction models of the labor market using micro data", The American Economic Review, September, Vol.92, No.4, 2002, see: http://www.econ.ohio-state.edu/johnham/final_AER4.pdf

Hamermesh, "Who Works When? Evidence form the US and Germany". NBER Working Paper, Number 5208, 1995.

Hamilton, J.D. “Time Series Analysis”, Princenton University Press, Princenton, NJ, USA, 678-699, 1994

Heckman, J. "Life-Cycle Consumption and Labour Supply: An explanation of the relationship between income and consumption over the life-cycle". The American Economic Review, 64, 188-194, 1974. 
Heckman, J., MaCurdy, T. “A Life-Cycle Model of Female Labour Supply”, Review of Economic Studies, 47, 47-74, 1980.

Krugman, P. "Inequality and the Political Economy of Eurosclerosis”, CEPR(London) Discussion Paper, 1993

Ljungqvist, L., Sargent, T. “Welfare States and Unemployment”, Economic Theory, Volume 6, Number 1, 143-160, 1995.

Ljungqvist, L., Sargent, T. “The European Unemployment Dilemma”, Manuscript, 1997.

Madison, J. "Federalist Papers”, Number 49. 1787

McGrattan, E.R, Rogerson, R. “Changes in hours worked since 1950”, Federal Reserve Bank of Minneapolis Quarterly Review, Vol.22, N0.1, Winter 1998, pages 2-19.

Muellbauer, J. "Habits, Rationality and Myopia in the Life-Cycle Consumption Function”, Annals of Economics and Statistics, 9, 47-70, 1988.

Mulligan, C. B. "Substitution over time: Another look at Life-Cycle labor supply", NBER Macroeconomics Annual, 1998, manuscript.

Nickell, S. "Unemployment and Labour Market Rigidities: Europe versus North America”, Journal of Economic Perspectives, V11, number 3, 55-74, 1997. OECD (1997) Employment Outlook, OECD, Paris, 1997, Tables A-C, F. OECD (1998) Employment Outlook, OECD, Paris, 1998, Tables A-C, F. OECD (1999) Employment Outlook, OECD, Paris, 1999, Tables A-C, F.

Siebert, H. "Labour Market Rigidities: At the root of unemployment in Europe”, Journal of Economic Perspectives, V11, Number 3, 37-54, 1997. 